\title{
Common Misconceptions Regarding Pediatric Auditory Processing Disorder
}

\author{
Vasiliki lliadou $^{1 *}$ and Christiane Kiese-Himmel ${ }^{2}$ \\ ${ }^{1}$ Neuroscience, Medical School, Aristotle University of Thessaloniki, Thessaloniki, Greece, ${ }^{2}$ Phoniatric and Pediatric \\ Audiological Psychology, University Medical Center Göttingen, Georg-August-University, Göttingen, Germany
}

Pediatric hearing evaluation based on pure tone audiometry does not always reflect how a child hears in everyday life. This practice is inappropriate when evaluating the difficulties children experiencing auditory processing disorder (APD) in school or on the playground. Despite the marked increase in research on pediatric APD, there remains limited access to proper evaluation worldwide. This perspective article presents five common misconceptions of APD that contribute to inappropriate or limited management in children experiencing these deficits. The misconceptions discussed are (1) the disorder cannot be diagnosed due to the lack of a gold standard diagnostic test; (2) making generalizations based on profiles of children suspected of APD and not diagnosed with the disorder; (3) it is best to discard an APD diagnosis when another disorder is present;

Edited by:

Raymond Van De Berg, Maastricht University Medical Centre, Netherlands

Reviewed by: Widdershoven Josine, Maastricht University Medical Centre, Netherlands

Anna Magnusson, Karolinska Institutet (KI), Sweden

*Correspondence: Vasiliki lliadou viliad@auth.gr

Specialty section: This article was submitted to Neuro-Otology,

a section of the journal

Frontiers in Neurology

Received: 11 October 2017 Accepted: 19 December 2017 Published: 23 January 2018

Citation:

lliadou V and Kiese-Himmel C (2018) Common Misconceptions Regarding Pediatric Auditory Processing Disorder. Front. Neurol. 8:732. doi: 10.3389/fneur.2017.00732 (4) arguing that the known link between auditory perception and higher cognition function precludes the validity of APD as a clinical entity; and (5) APD is not a clinical entity. These five misconceptions are described and rebutted using published data as well as critical thinking on current available knowledge on APD.

\footnotetext{
Keywords: auditory processing disorder, children, hearing, central auditory processing disorder, hearing evaluation, auditory processing disorder management, hearing management
}

Hearing acuity may be difficult to assess in children and does not always reflect how a child "hears" in everyday life. The audiological test battery must be built around the pure tone audiogram and may include tympanometry, stapedial reflexes, auditory brainstem responses, and otoacoustic emissions. However, relying on such a test battery to measure auditory function in the setting of school or playground in children referred for auditory processing deficits is incomplete (1). Auditory processing test batteries should be employed in these cases to more fully evaluate hearing in an ecological manner and fully examine how well the child hears outside the ideal conditions of the audiology lab. Auditory processing evaluation is known to tap into the physiological function and integrity of the Central Auditory Nervous System (CANS) providing more comprehensive information about the integrity of the entire auditory system and the functional hearing status of a child.

Internationally, there is a marked increase in interest of pediatric auditory processing disorder (APD) - also known as Central Auditory Processing Disorder (CAPD) — with a fourfold rise in published research during the last decade (Scopus database). The increased interest has not yet translated into availability of clinical evaluation services. Specialized clinics providing diagnosis and management of APD are scarce in most countries. As an example, some European countries are still in the process of standardizing their auditory processing test battery or attempting to optimize inclusion of imaging in diagnostics [i.e., Ref. (2-4)]. Consequently, many children with undiagnosed APD are 
struggling both in school and during out of school activities, with negative impact on their phonologic and prosodic communication, academics, psychosocial behavior, and social skills.

There are at least five common misconceptions regarding APD that may be contributing to inappropriate or limited management in children experiencing APD. The intent of this paper is to present each misconception with a brief commentary on the underlying reasons for the misconception, and to provide, if available, published data that substantiates the authors' perspective.

\section{MISCONCEPTION 1: WE CANNOT DIAGNOSE APD}

This misconception reflects: (a) the lack of a universal consensus on how many and which auditory deficits constitute an APD and (b) the lack of a universal standard for test inclusion and specific cut-offs for attributing the APD diagnosis to an individual.

A gold standard for any given diagnosis is a widely used method considered to be the best available (5). Current clinical practice guidelines recognizing the inherent complexity of any given disorder rely on a battery of tests to diagnose a disorder (6). The best available up to date are those described in AAA 2010 guidelines (7). Keeping them as a basis one can still expand and refine by using new diagnostic techniques while still comparing them with the best available.

The Clinical Practice Guidelines of the American Academy of Audiology (7) state on page 22: "Several audiologists with many years of experience in clinical assessment of CAPD have independently agreed on a similar criterion for the diagnosis of CAPD; that is, a score two standard deviations or more below the mean for at least one ear on at least two different behavioral central auditory tests" [e.g., Ref. (8-10)]. This criterion, which was based largely on studies of sensitivity and specificity obtained using various cut-off values for various central auditory tests to identify known CANS dysfunction, has also been recommended by ASHA (11). The German Society of Phoniatrics and Pedaudiology (12) recommends that the APD diagnosis be applied when the individual scores are at least two SDs below the age norm of the reference population on at least two auditory measures accompanied by specific symptoms that cannot be explained by other factors, such as attention, cognition, or peripheral hearing impairment (13). However, the evaluation of the clinical significance of the results as well as the number of measures/tests that should be performed is left to the diagnostician. Research examining the minimum number of tests required to validate a test battery is needed. Recently, Musiek et al. (14) and Weihing et al. (15) examined this question and reported that a two test combination (frequency pattern test and low-pass filtered speech for children) was the option providing the best efficiency. A European consensus paper (16) identifies five criteria for making an APD diagnosis: normal hearing sensitivity (threshold $\leq 15 \mathrm{~dB} \mathrm{HL}$ for each frequency between 250 and $8000 \mathrm{~Hz}$ in both ears), performance at or below 2 SD from the mean in at least 2 validated auditory processing tests that assess different processes in at least one ear (including non-speech sounds), presence of symptoms and risk factors related to APD, non-verbal intelligence coefficient $>80$ and ability of the individual to follow instructions in ideal conditions.

The authors identified several publications that seem to discard current APD protocols in school-aged children offering an abstract global approach that is not substantiated by appropriate research [e.g., Ref. (17)]. This approach may lead to failure to diagnose true hearing disorders (peripheral or central), and instead attribute symptoms to higher, supramodal, cognitive disorders. If proper audiological evaluation is not carried out, hearing loss can easily be misconstrued as an attention deficit (18). Moreover, some studies involve children with suspected but not diagnosed APD as participants (19-21). Children suspected of APD and children diagnosed with APD are two overlapping, but different groups. This means that conclusions reached about children suspected of APD cannot necessarily be generalized to children diagnosed with APD (22). Thus, there is a great need for additional research.

\section{MISCONCEPTION 2: VALID CONCLUSIONS CONCERNING APD CAN BE MADE WITHOUT ACTUALLY TESTING CENTRAL AUDITORY PROCESSING}

This confusion stems from the argument that the current APD testing battery does not adequately control cognitive and especially language variables.

Listening difficulties may result from many deficits and disorders (hearing loss included) and some researchers use the term APD to describe "listening difficulties" in children (19). They assert that if we cannot accurately diagnose APD, then we can base our suspicion of APD on symptoms, or use auditory tests without documented efficiency (23). This leads to statements about suspected APD that are taken by some as equivalent to diagnosis of the disorder. But without examining an individual's performance on an efficient central auditory test battery, it is impossible to sort out potential with cognitive measures nor reach conclusions regarding the true source of "listening difficulties" (16). It seems reasonable to assume that conclusions reached regarding APD based on diagnostic tests other than those that are of known efficiency and age-appropriate may not be contribute much to our understanding of APD (24).

\section{MISCONCEPTION 3: IF APD IS A SECONDARY DIAGNOSIS, THEN WE SHOULD DISCARD IT}

This misconception is an inappropriate extrapolation from the appropriate need for differential diagnosis, and ignores complexity and co-morbidity of neurodevelopmental disorders.

This statement (24) may lead to children not fully managed regarding their auditory processing problems both in and out of 
the classroom. The notion that a single diagnosis is valid for each child is not realistic as any clinician evaluating children knows. For example, there are transient hearing impairments that may coexist with problems to sustain attention in the presence of distractions or other attentional control deficits with resulting deterioration of the symptoms exhibited. Of interest, neurodevelopmental disorders often cooccur with APD (25) producing deficits (DSM-5, p. 31, line 7) ranging from specific limitations in learning to global impairments of intelligence, social interaction, or quality of life (26). Due to the high likelihood of comorbidity, an audiologist specialized in APD evaluation and management should request reports from speech-language pathologists, special educators, teachers, and psychologists-depending on a child's difficulties - in order to more effectively elect central auditory processing tests to administer and plan for management and treatment [e.g., Ref. $(27,28)]$. There are practical guidelines (29) that the clinician can use to minimize confounding cognitive and language variables for an adequate differential diagnosis of APD.

\section{MISCONCEPTION 4: APD REFLECTS COGNITIVE DEFICITS}

This statement is similar to the nature or nurture debate.

Auditory perception is a known contributing factor to the assessment of cognition (30), especially since most clinically used tests for verbal cognition rely on an individual's verbal reproduction of an item presented auditorily. Adults with peripheral hearing loss have been misdiagnosed as cognitively impaired due to this often overlooked contributing factor $(31,32)$. Short-term memory (STM) assessment is one of the most obvious measures that may lead to incorrect conclusions in the presence of uncorrected auditory dysfunction. In the absence of adequate hearing/audibility of test items, an individual may be incorrectly classified as having lower verbal STM. When hearing acuity is corrected (e.g., using a hearing aid, raising the intensity of the stimuli, or improved speech to noise ratio), the assessment will provide a more accurate measure of STM. Similarly, performance deficits on cognitive measures such as STM would not be an adequate explanation for the source of disparate disorders, such as language impairments, dyslexia, dyscalculia, ADHD, learning problems, or cognitive difficulties seen in autism. Moreover, correlation between APD and cognition does not impute a specific causal direction (33). It is essential that in the papers where APD is diagnosed and not just suspected, IQ cannot explain auditory processing deficits $(15,34)$. In a recent paper, the same applies for patients referred for APD testing (35).

\section{REFERENCES}

1. Musiek FE, Shinn J, Chermak GD, Bamiou DE. Perspectives on the pure-tone audiogram. J Am Acad Audiol (2017) 28:655-71. doi:10.3766/jaaa.16061

2. Kiese-Himmel C, Nickisch A. Diagnostische Genauigkeit einer AVWSTestbatterie in der Klassifikation von auffälligen und unauffälligen Kindern. Laryngorhinootologie (2015) 94:373-7. doi:10.1055/s-0034-1387766

\section{MISCONCEPTION 5: APD IS NOT A DISTINCT CLINICAL ENTITY}

\author{
This assertion relies on all previously refuted miscon- \\ ceptions $1-4$.
}

The accumulating body of research on APD over the last two decades led to the classification of APD in International Classification Disorder System (ICD), both the 10th and 11th editions $(36,37)$, as an "ear disease," thereby confirming that it is a physiological entity requiring medical attention. Moreover, APD is an accepted clinically recognized entity by many audiological societies throughout the world $(7,11,12,38-43)$. It is of interest that those researchers arguing that APD does not exist tacitly accept the existence of APD symptoms (19, 24, 44). They attribute these symptoms to attention and cognition without, apparently, recognizing the auditory perceptual contributions to cognition.

\section{CONCLUSION AND FUTURE RESEARCH}

The authors recognize that differential diagnosis is made difficult due to the overlapping symptoms across neurodevelopmental disorders and APD as well as many clinicians' limited education in interpreting results of auditory processing tests and disentangling them from results obtained by the multidisciplinary professional team, which sometimes are not even available for review. In future, these diagnostic challenges should be addressed through continuing in-depth education of audiologists and other health care professionals who are responsible for evaluating and managing children with APD. Audiologists would benefit from additional research with children diagnosed with APD focused on comparing new evaluation techniques with clinically validated approaches to ensure that new approaches meet the essential psychometric requirements and documented sensitivity to CANS lesions. The potential interactions between these new tools and cognitive, attention, and language indexes must also be examined. Standardizing these novel techniques across typically developing children and children with known brain pathology will provide further validation needed for clinical adoption to more effectively diagnose and treat APD.

\section{AUTHOR CONTRIBUTIONS}

VI had the original idea of the paper and have written the first draft together with $\mathrm{CKH}$. She subsequently edited and enhanced it to produce the final submitted form. $\mathrm{CKH}$ added arguments and enhanced the draft to produce the final submitted form.

3. Pedersen ER, Dahl-Hansen B, Christensen-Dalsgaard J, Brandt C. Implementation and evaluation of a Danish test battery for auditory processing disorder in children. Int J Audiol (2017) 56:538-49. doi:10.1080/14992027. 2017.1309467

4. Micallef LA. Auditory processing disorder (APD): progress in diagnostics so far. A mini-review on imaging techniques. J Int Adv Otol (2015) 11:257-61. doi:10.5152/iao.2015.1009 
5. Farlex Partner Medical Dictionary. (2012). Available from: http://medicaldictionary.thefreedictionary.com/gold+standard

6. Kasper DL, Hauser SL, Jameson JL, Fauci AS, Longo DL, Loscalzo J. Harrison's Principles of Internal Medicine. 19th ed. New York: McGraw-Hill Medical Publishing Division (2015).

7. American Academy of Audiology (AAA). Practice Guidelines for the Diagnosis, Treatment, and Management of Children and Adults with Central Auditory Processing Disorder (CAPD). (2010). Available from: https://audiology-web.s3.amazonaws.com/migrated/CAPD\%20Guidelines\%208-2010. pdf_539952af956c79.73897613.pdf

8. Bellis TJ. Assessment and Management of Central Auditory Processing Disorders in the Educational Setting: From Science to Practice. Clifton Park, NY: Thomson Learning, Inc (2003). $271 \mathrm{p}$.

9. Chermak G, Musiek FE. Central Auditory Processing Disorders: New Perspectives. San Diego: Singular Publ Group (1997). p. 370-6.

10. Musiek FE, Chermak G, Weihing J. Auditory training. In: Chermak GD, Musiek FE, editors. Handbook of (Central) Auditory Processing Disorder: Comprehensive Intervention. (Vol. 2), San Diego: Plural Publishing (2007). p. 77-106.

11. American Speech-Language-Hearing Association (ASHA). Technical Report. Central Auditory Processing Disorders. (2005). Available from: http://www. asha.org/policy/TR2005-00043/

12. Deutsche Gesellschaft für Phoniatrie und Pädaudiologie (DGPP). Leitlinie Auditive Verarbeitungs- und Wahrnehmungsstörungen. (2017). Available from: http://www.awmf.org/leitlinien/detail/1//049-012.html

13. Nickisch A, Gross M, Schönweiler R, Berger R, Wiesner T, Am ZehnhoffDinnesen A, et al. Auditive Verarbeitungs- und Wahrnehmungsstörungen (AVWS): Zusammenfassung und aktualisierter Überblick. HNO (2015) 63:434-8. doi:10.1007/s00106-015-0002-0

14. Musiek FE, Chermak GD, Weihing J, Zappulla M, Nagle S. Diagnostic accuracy of established central auditory processing test batteries in patients with documented brain lesions. J Am Acad Audiol (2011) 22:342-58. doi:10.3766/ jaaa.22.6.4

15. Weihing J, Guenette L, Chermak GD, Brown M, Ceruti J, Fitzgerald K, et al. Characteristics of pediatric performance on a test battery commonly used in the diagnosis of central auditory processing disorder (CAPD). J Am Acad Audiol (2015) 26:652-69. doi:10.3766/jaaa.14108

16. Iliadou V, Ptok M, Grech H, Pedersen ER, Brechmann A, Deggouj N, et al. A European perspective on auditory processing disorder-current knowledge and future research focus. Front Neurol (2017) 8:622. doi:10.3389/ fneur.2017.00622

17. DeBonis DA. It is time to rethink central auditory processing disorder protocols for school-aged children. Am JAudiol (2015) 24:124-36. doi:10.1044/2015_AJA-14-0037

18. Iliadou V, Sirimanna T, Bamiou DE. CAPD is classified in ICD-10 as H93.25 and hearing evaluation-not screening-should be implemented in children with verified communication and/or listening deficits. Am J Audiol (2016) 25:368-70. doi:10.1044/2016_AJA-16-0055

19. de Wit E, Visser-Bochane MI, Steenbergen B, van Dijk P, van der Schans CP, Luinge MR. Characteristics of auditory processing disorder: a systematic review. J Speech Lang Hear Res (2016) 59:384-413. doi:10.1044/2015_JSLHR$\mathrm{H}-15-0118$

20. Ahmmed AU, Ahmmed AA, Bath JR, Ferguson MA, Plack CJ, Moore DR. Assessment of children with suspected auditory processing disorder: a factor analysis study. Ear Hear (2014) 35:295-305. doi:10.1097/01.aud. 0000441034.02052.0a

21. Rosen S, Cohen M, Vanniasegaram I. Auditory and cognitive abilities of children suspected of auditory processing disprder (APD). Int JPediatr Otorhinolaryngol (2010) 74:594-600. doi:10.1016/j.ijporl.2010. 02.021

22. Chermak GD, Musiek FE, Weihing J. Beyond controversies: the science behind central auditory processing disorder. Hearing Rev (2017) 24:20-4.

23. Moore DR, Ferguson MA, Edmondson-Jones AM, Ratib S, Riley A. Nature of auditory processing disorder in children. Pediatrics (2010) 126:382-90. doi:10.1542/peds.2009-2826

24. Neijenhuis K, de Wit E, Luinge M. Perspectives of Dutch health professionals regarding auditory processing disorders; a focus group study. Int J Audiol (2017) 13:1-9. doi:10.1080/14992027.2017.1347290

25. American Psychiatric Association. Diagnostic and Statistical Manual of Mental Disorders. 5th ed. Washington, DC: American Psychiatric Association (2013).
26. Kreisman NV, John AB, Kreisman BM, Hall JW, Crandell CC. Psychosocial status of children with auditory processing disorder. J Am Acad Audiol (2012) 23:222-33. doi:10.3766/jaaa.23.3.8

27. Witton C. Childhood auditory processing disorder as a developmental disorder: the case for a multi-professional approach to diagnosis and management. Int J Audiol (2010) 49:83-7. doi:10.3109/14992020903289808

28. Sharma M, Purdy SC, Kelly AS. A randomized control trial of interventions in school-aged children with auditory processing disorders. Int J Audiol (2012) 51:506-18. doi:10.3109/14992027.2012.670272

29. Chermak GD, Bamiou DE, Iliadou V, Musiek F. Practical guidelines to minimise language and cognitive confounds in the diagnosis of CAPD: a brief tutorial. Int J Audiol (2017) 56:499-506. doi:10.1080/14992027.2017.1284351

30. Lindenberger U, Scherer H, Baltes PB. The strong connection between sensory and cognitive performance in old age: not due to sensory acuity reductions operating during cognitive assessment. Psychol Aging (2001) 16:196-205. doi:10.1037/0882-7974.16.2.196

31. Dupuis K, Pichora-Fuller MK, Chasteen AL, Marchuk V, Singh G, Smith SL. Effects of hearing and vision impairments on the Montreal Cognitive Assessment. Neuropsychol Dev Cogn B Aging Neuropsychol Cogn (2015) 22:413-37. doi:10.1080/13825585.2014.968084

32. Jorgensen LE, Palmer CV, Pratt S, Erickson KI, Moncrieff D. The effect of decreased audibility on MMSE performance: a measure commonly used for diagnosing dementia. J Am Acad Audiol (2016) 27:311-23. doi:10.3766/jaaa.15006

33. Iliadou V, Bamiou DE, Sidiras C, Moschopoulos NP, Tsolaki M, Nimatoudis I, et al. The use of the gaps-in-noise test as an index of the enhanced left temporal cortical thinning associated with the transition between mild cognitive impairment and Alzheimer's disease. J Am Acad Audiol (2017) 28:463-71. doi:10.3766/jaaa.16075

34. Iliadou V, Bamiou DE, Kaprinis S, Kandylis D, Kaprinis G. Auditory processing disorders in children suspected of learning disabilities - a need for screening? Int J Pediatr Otorhinolaryngol (2009) 73:1029-34. doi:10.1016/j. ijporl.2009.04.004

35. Brenneman L, Cash E, Chermak GD, Guenette L, Masters G, Musiek FE, et al. The relationship between central auditory processing, language, and cognition in children being evaluated for central auditory processing disorder (CAPD), J Am Acad Audiol (2017) 28:758-69. doi:10.3766/jaaa.16119

36. World Health Organisation. ICD-10 Classifications of Mental and Behavioural Disorder: Clinical Descriptions and Diagnostic Guidelines. Geneva: WHO (1992).

37. World Health Organisation. ICD-11 International Statistical Classification of Diseases and Related Health Problems, $11^{\text {th }}$ Revision. Available as "CD-11 Beta Draft" at: https://icd.who.int/dev11/l-m/en

38. Bureau International d' Audiophonologie in Belgium. (2017). Available from: https://www.biap.org/fr/bureau-international-d-audiophonologie

39. British Society of Audiology (BSA). Position Statement and Practice Guidance, Auditory Processing Disorder (APD). (2017). Available from: http://www. thebsa.org.uk/wp-content/uploads/2017/04/APD-Position-StatementPractice-Guidance-APD-2017.pdf

40. Canadian Interorganizational Steering Group for Speech-Language Pathology and Audiology. Canadian Guidelines on Auditory Processing Disorder in Children and Adults: Assessment \& Intervention. (2012). Available from: http:// www.ooaq.qc.ca/publications/doc-documents/Canadian_Guidelines_EN.pdf

41. Danish Medical Audiological Society. (2014). Available from: http://dmasaud. $\mathrm{dk} /$ onewebmedia/DSOHH-KKR-APD.pdf

42. Esplin J, Wright C. Auditory Processing Disorder: New Zealand Review. A Report Prepared for the Ministry of Health and Ministry of Education. (2014). Available from: https://www.health.govt.nz/system/files/documents/ publications/auditory_processing_disorder.pdf

43. Dillon H, Cameron S. National Acoustic Laboratories (NAL) Position Statement on Auditory Processing Disorders. (2015). Available from: https://capd.nal.gov. au/capd-position-statement.shtml

44. Vermiglio AJ. On the clinical entity in audiology: (central) auditory processing and speech recognition in noise disorders. J Am Acad Audiol (2014) 25:904-17. doi:10.3766/jaaa.25.9.11

Conflict of Interest Statement: The authors declare that the research was conducted in the absence of any commercial or financial relationships that could be construed as a potential conflict of interest.

The reviewer JW and handling Editor declared their shared affiliation. 
Copyright (c) 2018 Iliadou and Kiese-Himmel. This is an open-access article distributed under the terms of the Creative Commons Attribution License (CC BY). The use, distribution or reproduction in other forums is permitted, provided the original author(s) or licensor are credited and that the original publication in this journal is cited, in accordance with accepted academic practice. No use, distribution or reproduction is permitted which does not comply with these terms. 